\title{
Studies on Skin Sensitivity to Various Allergens in Jeddah, Saudi Arabia Using Skin Prick Test
}

\author{
Eman Beyari and Hussein A. Almehdar \\ Biological Sciences Department, Faculty of Science, King Abdulaziz University, Jeddah, Saudi Arabia,
}

\begin{abstract}
Skin prick test is one of the more important diagnostic tests against allergic diseases, it uses a synthesized allergic extracts from different allergens. In this study skin prick test was done on 83 allergic persons and 20 controls (54 male and 49 female). The test was done in the Allergic Clinic in the King Abdulaziz University Hospital with 9 different allergens which were isolated from Jeddah city. The used allergens were extract of 2 species of house dust mite, extract of house dust and extracts of 6 species of identified fungi. The extracts were used in the skin prick test and compared with the same commercial allergen extracts, imported from Omega company, Canada. The results revealed a significant difference between the two results and the Canadian extracts were better than the Saudi extracts. Conclusion: From the over mentioned results could concluded that the Saudi allergens able to be applied and gave the valuable results if compared with the imported Canadian allergens which isvery expensive using skin prick test. Also the Saudi allergens need more studies to standardize to give promising economic impact results.
\end{abstract}

Keywords: Allergerns, Skin prick, Patients, Diagnosis

\section{Introduction}

In 1873, Charles Blackley rubbed pollens on a braded skin to give us the first descripton of skin prick test. Skin prick test is now an essential test procedure to diagnose allergic diseases (Arshad 2009). A part of world population (20\%) suffered from allergic diseases including eczema, asthma, and anaphylaxis (Khadadah et al., 2000, Johansson and Haahtela, 2008). Airway allergy is a disease, occured by non specific target organ but rather a disorder of the whole respiratory tract. Clinical studied as well as experimental observations suggested that there is a link between rhinitis and asthma which lead to a definition of airways diseases (Aas and Belin, 1974, Simons, 1994). The prevalence of allergy has increased in last two to three decades possibly due to change in indoor and outdoor environment (Prasad et al., 2001). Allergens are protein molecules capable of stimulating an immune response and can cause and trigger nasobronchial allergy. Prick may be very useful to identify the offending allergen. The present study was done to study the skin sensitivity to various allergens by skin prick test in patients of nasobronchial allergy. These allergens can be found in house dust mites, fungi, food, insects, and pollen grains and may couse allergic diseases which could be determined by Skin test. Skin test should be considered as a laboratory aid and interpreted with reference to the information available from history and physical examination. Skin prick test can diagnose eczema, allergic rhinitis, allergic conjunctivitis, urticaria, anaphylaxis, eczema and food allergy (Heinzerling et al. 2013). The test can be done from the birth to old ages. Repeating test some times may be important to detect new sensitization espically in children when new sypmtoms appear. The recommended method of prick testing includes the appropriate use of specific allergen extracts, positive and negative controls. The test was done in the volar surface of the arm and also the test can be done in the back. Many companies can synthetize allergens to be used in skin test and the esults appeared after 15-20 minutes of application. The results will be positive if the wheal is equal or larger than 3 $\mathrm{mm}$ in diameter. The aim of this study was to test some allergens from house dust mites, house dust and fungi, collected from different areas of Jeddah city and compared their activities with that of the imported allergens from Canada.

\section{Materials and Methods}

The study was conducted among 103 persons of different ages of both allergic and non-allergic people. The sample was 83 allergic persons and 20 controls and the sample was 54 male and 49 female. Pregnant and lactating females were excluded from the study. All the patients were subjected to detailed history and clinical examination.

\subsection{The tested materials:}

In this research , 9 different allergens were isolated from Jeddah city , 2 species of house dust mite ( Dermatophagoides farinae and Dermatophagoides pteronyssinus), house dust and 6 samples of fungi including Candida albicans, Aspergillus fumigatus, Alternaria alternata, Penicillium chrysogenum, Cladosporium herbarum and Fusarium solani (Hasnain et al., 1995). 


\subsection{The house dust samples}

Dust samples were collected by vacuum cleaner from bedrooms, bedding, floor carpets, bed sheets, blankets and pillows. Each sample collected by vacuuming $1 \mathrm{~m}^{2}$ of surface area for 4 minutes. The dust was collected in changeable vacuum cleaner bags and each sample with its information sheet enclosed in a plastic bag, tied securely and sent to the laboratory within 24 hours of collection.

\subsection{The house dust mite samples}

The house dust mite samples represented various standard of houses and these selected houses represented two socioeconomic classes of the community, some use neither vacuum cleaners nor airconditioning system, while the others use electrical cleaners and air-conditioning system during summer and winter seasons (Hessen and Lund 2002 ; Jackson et al. 2005). Living mites isolated from dust by a modified Berlese funnel with wire screening. Each sample of dust placed on the top of the wire screening and covered with the lid of a Petri dish, large enough to cover the dust. A small water filled beaker placed beneath the funnel and a 60 watt lamp hung at $20 \mathrm{~cm}$ above the apparatus. After 24 hours, the water surface of the first beaker examined under a stereomicroscope (Koraiem and Fahmy, 1999, Schei et al., 2002). Mites cultured under controlled laboratory conditions by keeping two to four grams of fine house dust sample in a special synthesized pot for two to three weeks, at optimum temperature $25^{\circ} \mathrm{C}$ and humidity $(\mathrm{RH})$ of $75 \%$ in special incubator. The mite's food is composed of dry powdered cheese which dried in the ultraviolet furnace, dried eggs and yeast. The mixture of food added in a ratio of 1: 1: 2 (Saied 1990; Mostafa 1998). After sixteen days the mites isolated with a fine dissecting needle from this mixture and put into the special pot and then isolated from the mixture by using the same previous method, after that, the mites were killed by freezing them, left them in the freezer until used for extraction.

\subsection{Fungal samples}

Fungi were isolated from indoor and outdoor by using culture plate method. The exposed plates were incubated at room temperature for 5-7 days, after that, the colonies were purified, and identified. Each fungal was grown in liquid broth medium and the growth were isolated from the media and were put in a clean flask, killed them by adding absolute ethanol to the growth for two hours. Then, the growth was dried in oven for two or three days at $45^{\circ} \mathrm{C}$ (Hasanin et al. 1995).

\subsection{Extraction of samples}

The house dust, powdered fungi and house dust mites samples were extracted by using coca solution ( 5 gm sodium chloride, $2.75 \mathrm{gm}$ sodium bicarbonate, $4 \mathrm{gm}$ phenol crystals and 1 litre distilled water ) (Mostafa 1998), at the concentration 1:10 (weight per volume technique). About $1 \mathrm{gm}$ of each allergen was added to $9 \mathrm{ml}$ of coca solution, the $\mathrm{pH}$ was 7.5-8. The mixture was grounded and shacked in a shacker at room temperature for two hours daily for 3 days (Horner et al. 1995), filtrated through filter paper (Whatman no 1) (Mason 1995), defatted by using diethyl ethar, then a second filtration is done through seitz filter $0.22 \mu$ to kill the germs (Al Frayh et al. 1997), added $50 \%$ glycerin to the extract. The extracts were cultured on nutrient and blood agar under aerobic and non aerobic conditions for 15 days, to check the sterility and to be sure there is no microbial growth in the extracts.

\subsection{Commetial extracts}

The different commetial allergen extracts were imported from Omega Company, Canada.

\subsection{Alergic test}

The skin prick test was done on 103 persons (20 of them were control and 83 allergic persons), the study contained 54 male and 49 female, and the test was done in the Allergic Clinic in the king Abdulaziz University Hospital, Jeddah. The test was done on one hand and the Canadian test on the other hand, and then the results of the two tests were compared.

\subsection{Statistical analysis:}

Statistical analysis was done using the statistical program SPSS ver 12 and one Way ANOVA Test was performed. The statistical program was assess the effectiveness of the prepared extracts compared to the commercial extracts.

\section{Results}

The skin prick test was revealed that $84.34 \%$ of the respondents gave a positive reaction to one allergen or more, while $15.66 \%$ did not give any positive reactions. The results showed that the average diameters resulting from skin prick test in Saudi prepared extract was $1.3 \mathrm{~mm}$ with a standard deviation of 2.05 , while the average diameters was $1.6 \mathrm{~mm}$ in the Canadian commerial extract with a standard deviation of 2.7 (Table 1). The results proved that the $\mathrm{P}$ value was 0.000 which indicates the presence of significant correlation 
between the two examined extracts. The compared results revealed that the ratios achieved by both extracts were different and were as follows: $61.8 \%$ of the samples were equal in both extracts. The Canadian extract showed $21 \%$ of the samples better than Saudi prepared extract as higher or wider diameter. Saudi prepared extract was better than Canadian with the percent of $17.2 \%$ (Fig. 1).

Table 1: Characteristics of Saudi and the Canadian extracts

\begin{tabular}{|r|r|}
\hline Extract & Mean \pm Std \\
\hline Saudi prepared extract & $1.3122 \pm 2.0450$ \\
\hline Canadian extract (omega) & $1.5575 \pm 2.6662 *$ \\
\hline \multicolumn{2}{|c|}{$* P<0.05$ indicates a significant correlation }
\end{tabular}

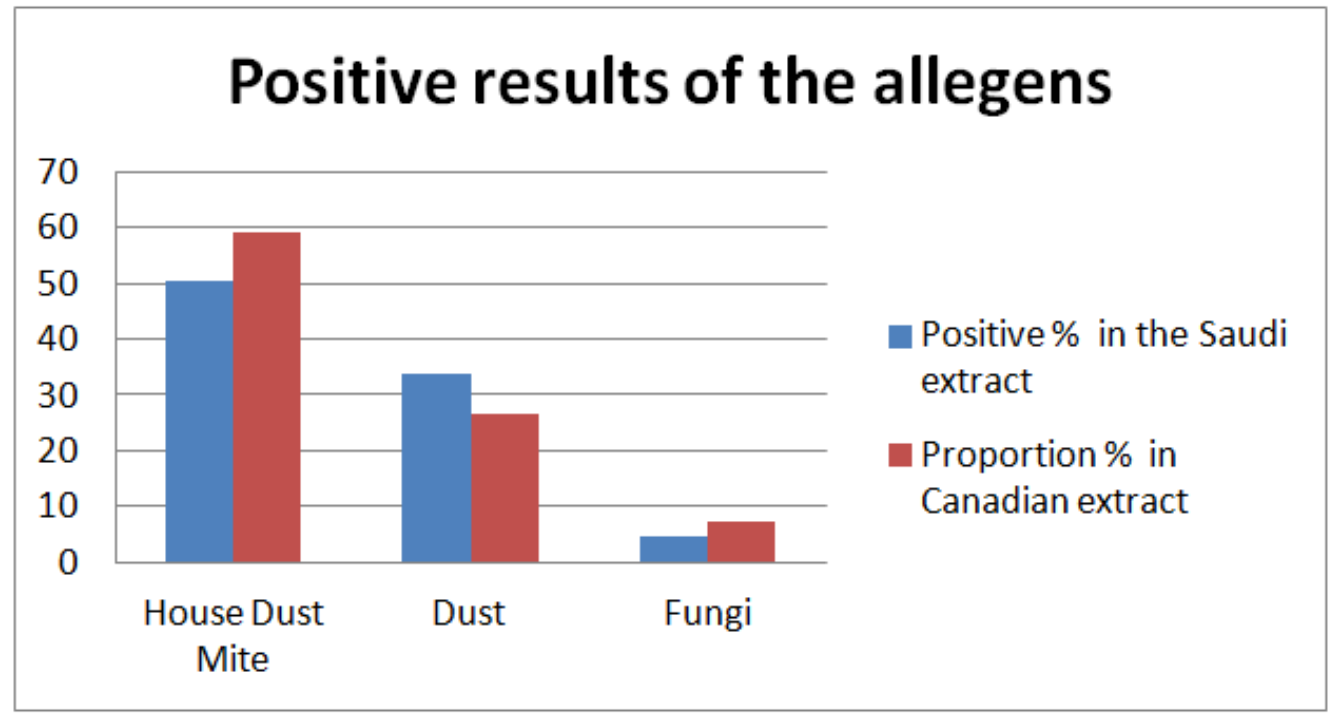

Figure 1. The positive results of the two tested extracts

House Dust Mites gave higher positive ratio in the sample, followed by dust, and the fungi were the lowest. The proportion of positive results of house dust mites in the Saudi prepared extracts was $50.6 \%$ and the result was $59.1 \%$ for the Canadian extract. The percentage of positive results of the dust was $33.7 \%$ in the Saudi prepared extract and $26.5 \%$ in the Canadian extract, it is clear that the highest percentage was in the Saudi prepared extract. For fungi, the proportion of positive results in the Saudi prepared extract was $4.6 \%$ and $7.4 \%$ in Canadian extract, the higher percentage here in Canadian extract. Table 2 showed the positive results of the allergens of the two tested extracts, Saudi prepared and Canadian extracts.

Table 2: Allergens that gave positive reaction of the two tested extracts, Saudi prepared and Canadian extracts.

\begin{tabular}{|l|l|l|}
\hline Allergens & $\begin{array}{l}\% \text { of positive results in the Saudi } \\
\text { extract }\end{array}$ & $\begin{array}{l}\% \text { of positive results in the Canadian } \\
\text { extract }\end{array}$ \\
\hline House Dust Mite & 50.6 & 59.1 \\
\hline Dust & 33.7 & 26.5 \\
\hline Fungi & 4.6 & 7.4 \\
\hline
\end{tabular}

The percent of Canadian extract showed higer positive in all allergens except house dust extract gave a higher percentage in the Saudi extract and fungus Alternaria alternata gave equal percentrs. Table 3 showed the percentages of positive skin test for each individual respose in both Saudi and Canadian extracts and Pvalues for each individual respose. The results demonstrated no significant difference to the average diameters of positive results between Saudi and Canadian extracts of each allergens except in extracts of $D$. farinae and D. pteronyssinus and A. Fumigatus (value>0.05), where significant difference between the mean diameters of positive results, where the $\mathrm{P}$ value $<0.05$. 
Table 3: Positive cases and percentages of the skin test for each individual respose in both Saudi and Canadian extracts

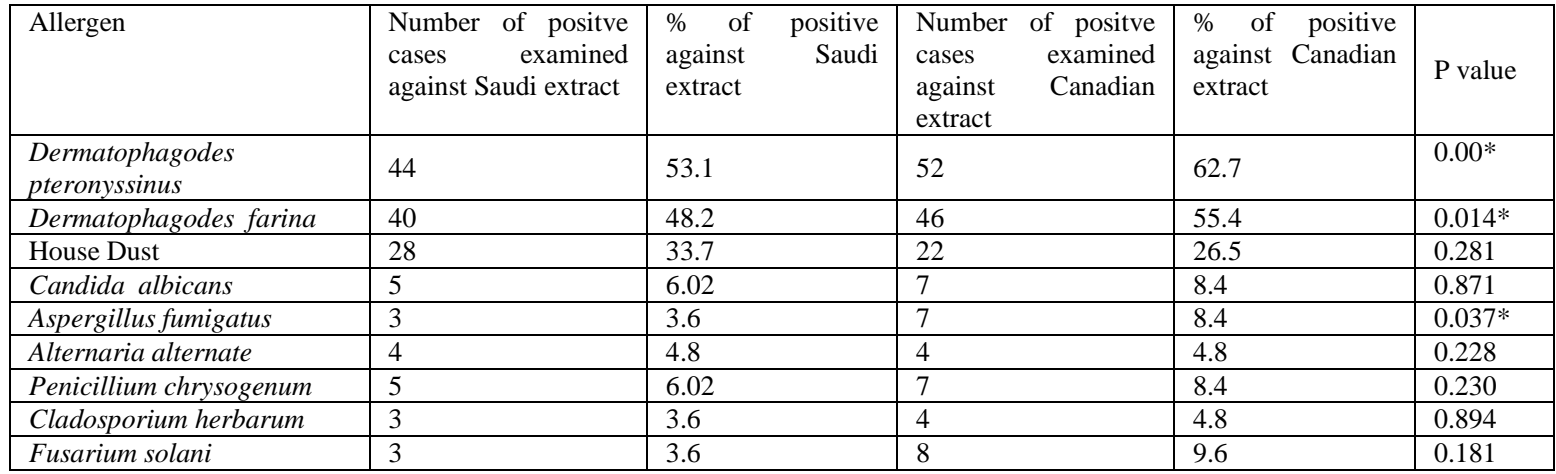

$* P<0.05$ indicates a significant difference

It was clear from the results that there is no significant difference between the average male and female community $(\mathrm{P}$ value $=0.235$ any $\mathrm{P}$ value $>0.05$ ) which shows the equality of male and female when having allergies. Evidenced by the statistical analysis that confirms the absence of significant correlation between the diseases and skin prick test $(\mathrm{P}$ value $=0.358$ any that $\mathrm{P}$ value $>0.05)$. The different types of diseases do not affect the skin test results. The prevalence of allergic diseases in the sample: Allergic rhinitis gave the highest percentage in allergic diseases (36.4\%), followed by asthma and eczema (18.9\%), allergic conjunctivitis $(15.4 \%)$ and urticaria $(4.9 \%)$, followed by sinusitis $(4.2 \%)$ and finally anaphylaxis $(1.4 \%)$. The statistical analysis proves that there is no relationship between age and skin test ( $\mathrm{P}$ value $=0.121$ any $\mathrm{P}$ value $>0.05)$, in the sense that the skin test results were not affected by age or change up or deficiency.

\section{Discussion}

The results of this study revealed that there is a significant difference between the results of Canadian and Saudi extracts, Canadian extracts gave higher results than the Saudi extract. They does not comply with the study conducted in 2002 in Egypt to compare 14 local and imported extract from Allergopharma company for the diagnosis of conjunctivitis (Haggag 2002). The difference in results is may be due to the difference in extraction method, where some companies extract allergens in pure form without the presence of any impurities, it is known that these impurities reduce positive results reactions in skin prick test. For examples, The primary cause of allergy in the House Dust Mite are stool or some body parts of the house dust mite, as well as in fungi, allergen is small portion, while in extracting method whole body of house dust mite and fungi were extracted. Foreign companies can make extract without removing the allergen from the causes, by knowing the amino acids constituting in allergen, they can easily synthesize them, which gives a pure form for every allergen. Moreover, different results may be caused by different strains of species isolated from the two different countries, and may be caused by different solvents and concentration used in the extraction or different temperature or to the different environments used for the development of fungi or to the different food used for the development of the house dust mite.

Regarding to the results of this study also found that males and females were equally to disease sensitivity, and this result agrees with study on patients with asthma and allergic rhinitis in the city of Perugia in Italy (Siracusa et al. 1997), where the prevalence of diseases equal in both sexes, and contrary to this finding study conducted in allergic rhinitis in Saudi Arabia (AL Nahdi and Qurain 1989), in Poland (Jedryshoweski et al. 2000), Spain (Gaig et al. 2004), Austria (Dorner et al. 2008), Brazil (De Fatima Macaira et al. 2007) and in Denmark (Thomsen et al. 2004).

Concerning to the age the study stated that the different stages of life do not affect the results of skin test, in the sense that it does not increase or decrease in a certain age, these results do not correspond with the results of which was clarified in the United States of America (Stern et al. 2004) (Montealegre et al. 2004), in Hong Kong (Yuen et al. 2007) and contradicted these studies Other studies, including the study conducted in Austria (Dorner et al.2008) and in America (Calabria and Dice et al. 2007).

In previous studies, there is no confirmation that one gender has more allergy than the other in all circumstances, and allergy diseases also do not affect people in certain age. The difference may be due to the difference in the environment, race, country, pollution, the number and type of sample and other reasons.

In addition, for the diseases the prevalence of asthma was $18.9 \%$ of the sample, while allergic rhinitis occupy the highest percentage of diseases, amounting to $36.4 \%$, and rate of allergic rhinitis does not vary when compared with rates spread in other countries of the world, while we note the variation in asthma, for example, the prevalence of allergic rhinitis in the city of Uberlandia in Brazil was 32\% and for asthma 1.9\% (Soares et al. 2007) and in the city of Sao Paulo the proportion of asthma in workers health clinics was $11 \%$ and the 
proportion of allergic rhinitis was 35\% (De Fatima et al. 2007). In the United States the rate of asthma achieved 30.5\% and allergic rhinitis 31.3\% (Montealegre et al. 2004), In Turkey, the percentage of asthma reached 40\% (Erel et al. 1998).

The Saudi allergen extract Dermatophagoides pteronyssinus caused positive results in $53.01 \%$ of the sample and the Canadian extract gave positive results in $62.7 \%$, and the species Dermatophagoides farinae gave $48.2 \%$ in the Saudi extracts and $55.4 \%$ in the Canadian extracts, illustrated by the results of extracts that species Dermatophagoides pteronyssinus caused higher sensitivity than the other one, These results are consistent with multiple studies. In Jeddah, a study was conducted on patients with asthma and the results of skin test were positive for allergen Dermatophagoides pteronyssinus by $87 \%$ of the sample, and $84 \%$ of the allergen Dermatophagoides farina (Koshak, 2006) and also conducted another study in the city of Jeddah on patients with allergic rhinitis and the results of skin test were positive for species Dermatophagoides pteronyssinus in $70 \%$ of the sample, while giving $67 \%$ for species D. farinae (Koshak et al. 2005) and in Kuwait skin test results were positive for asthma in $28 \%$ of the sample to house dust mites and in Palestine species Dermatophagoides pteronyssinus was wide spread in mattress cots and living floor dramatically, as was the rate of high camps shelters, and found species Dermatophagoides farinae but rates very low compared with the opposite species (El Sharif et al. 2004) and in Qatar skin prick test was positive in 51.4\% of patients with asthma and allergic rhinitis, and $41.6 \%$ of patients showed reaction positive to House Dust Mite Dermatophagoides pteronyssinus and $36.9 \%$ of patients showed interaction positive towards Dermatophagoides farina (Sattar et al. 2003). Study the ratio sensitivity of House Dust Mite in asthma patients in Turkey, and the proportion was $37.7 \%$ of the sample (Uzel et al. 2005), in another study in Turkey also rate was fumbling of House Dust Mite 20.5\% (Erel et al. 1998). In America, the percentage of allergy to House Dust Mite in one study reached to $94.3 \%$ (Montealegre et al. 2004) and a study was conducted in Dallas to see the most important allergens that cause asthma in children aged 5-11 years, House Dust Mite was the most important allergens where it formed $62 \%$ of allergens (Gruchalla et al. 2005).

\section{Conclusions}

From the results of this study can concluded that the Canadian extract gave better results than Saudi prepared extract, but taken into consideration that the Saudi extract gave positive results, and that their relationship was positive correlation. The results of Canadian extract was higher than Saudi prepared extracts which need more efforts to reach the efficiency of imported extract which was obtained fron Canda.

\section{References}

[1]. Aas K, Belin L. (1974). Suggestion for biologic qualitative testing and standardization of allergen extracts. Acta Allergol., 29:23840.

[2]. Al Frayh, A., Hasnain, S., Gad Al Rab, M., Schwarts, B. and Al Sedairy, S. (1997) House Dust Mite Allergen in Saudi Arabia Region Variations and Immune Response, Annals of Saudi Arabia 17(2) : 156- 160.

[3]. Al Nahdi, M. and Al Qurain, A. (1989) IgE level in Saudi Arabia. Allerg Immunol., 21(8):308-310.

[4]. Arshad, S.H. (2002) Allergy, London: Churchill Livingstone.

[5]. De Fátima Maçãira, E. Algranti, E. Medina Coeli Mendonça, E. and Antônio Bussacos, M. (2007). Rhinitis and asthma symptoms in non-domestic cleaners from the Sao Paulo metropolitan area, Brazil, Occup Environ Med. 64(7):446-453.

[6]. Dorner, T. Lawrence, K. Rieder, A. Kunze, M. (2008) Epidemiology of allergies in Austria: Results of the first Austrian allergy report, Wien Med Wochenschr., 157 (11-12):235-242.

[7]. El Sharif, N. Douwes, J. Hoet, P.H. Doekes, G. and Nemery, B. (2004) Concentrations of domestic mite and pet allergens and endotoxin in Palestine, Allergy. 59(6):623-631.

[8]. Erel, F. Karaayvaz, M. Calişkaner, Z. and Ozangüç, N.(1998) The allergen spectrum in Turkey and the relationships between allergens and age, sex, birth month, birthplace, blood groups and family history of atopy, J Investig Allergol Clin Immunol. (4):226-233.

[9]. Gaig, P. Olona, M. Muñoz Lejarazu, D. Caballero, MT., Domínguez, FJ. Echechipia, S. García Abujeta, JL. Gonzalo, MA. Lleonart, R. Martínez Cócera, C. Rodríguez, A. and Ferrer, M. (2004). Epidemiology of urticaria in Spain, J Investig Allergol Clin Immunol. 14(3):214-220.

[10]. Gruchalla, R.S. Pongracic, J. Plaut, M. Evans, R3 ${ }^{\text {rd }}$. Visness, C.M.Walter, M. Crain, E.F. Kattan, M. Morgan, W.J. Steinbach, S. Stout, J. Malindzak, G. Smartt, E. and Mitchell, H. (2005). Inner City Asthma Study: relationships among sensitivity, allergen exposure, and asthma morbidity, J Allergy Clin Immunol. 115 (3):478 - 485.

[11]. Haggag, M.G. (2002). A comparative study between local and commercial allergens in diagnosis of allergic conjunctivitis , Ph.D Thesis , Cairo university, Cairo.

[12]. Hasnain, S.M., Al Frayh, A. S., Al Suwaini, A.R., Gad El Rab, M.O., Harfi, H.A. and Al Sedairy S. (1995) Allergenic Implication of airborne Ulocladium in Saudi Arabia, Grana, 34: 70 - 76

[13]. Heinzerling L, Mari A, Bergmann KC, Bresciani M, Burbach G, Darsow U, Durham S, Fokkens W, Gjomarkaj M, Haahtela T, Bom AT, Wöhrl S, Maibach H, Lockey R.(2013) The skin prick test - European standards, Clin Transl Allergy, 33: 12-19.

[14]. Hessen, J.O. and Lund, E. (2002) House-dust mites and Mattresses, Allergy, 57(6): 538 - 542.

[15]. Horner, W. E. Helbling, A. Salvaggio, J.E. and Lehrer, S.B.( 1995) Fungal Allergens, clinical microbiology, 8 (2) : 161 - 170.

[16]. Jackson, A.P. Foster, A.P. Hart, B.J. Helps, C.R. and Shaw, S.E. (2005). Prevalence of house dust mites and Dermatophagoides group 1 antigens collected from bedding, skin and hair coat of dogs in south-west England, Vet Dermatol., $16(1): 32$ - 38.

[17]. Jedrychowski, W. Flak, E. Mróz, E. and Lis, G. (2000). Sensitization to common airborne allergens in school children with bronchial asthma, Przegl Lek. 57(9):441-445. 
[18]. Johansson SGO, Haahtela T. (2008). World Allergy Organization Guidelines for Prevention of Allergy and Allergic Asthma. World allergy organization guidelines. Available from: http://www.worldallergy.org/WAD2005/index.html. Accessed June 25, 2008

[19]. Khadadah, M. Onadeko, B.O. Ezeamuzie, C.I. Mustafa, H.T. Marouf, R. and Sugathan, T.N. (2000) The association of skin test reactivity, total serum IgE levels, and peripheral blood eosinophilia with asthma in Kuwait, J Asthma. 37(6):481-488.

[20]. Koraiem, M.K.Y. and Fahmy, I.A. (1999). Styudy on house dust mites in great cairo , Egypt, Journal of Egyptian Society of Parasitology, 29(1): $131-138$.

[21]. Koshak, E. A. (2006) Skin Test Reactivity to Indoor Allergens Correlates with Asthma Severity in Jeddah, Saudi Arabia, Allergy. Asthma, and Clinical Immunology , 2(1):11-19.

[22]. Koshak, E.A. Backer, W.S. Daghistani, K.J. and Jamal, T.S. (2005) Allergy Workup in Allergic Rhinitis, Saudi Journal of OtoRhino-LaryngologyHead and Neck Surgery, 7(2):92-97.

[23]. Mason, W.W. (1995). Preparation of antigens for the diagnosis and treatment of allergy , part 2 : extraction of raw materials, ENT journal.

[24]. Montealegre, F. Meyer, B. Chardon, D. Vargas, W. Zavala, D. Hart, B. and Bayona, M. (2004) Comparative prevalence of sensitization to common animal, plant and mould allergens in subjects with asthma, or atopic dermatitis and/or allergic rhinitis living in a tropical environment, Clin Exp Allergy. 34(1):51-58.

[25]. Mostafa, W.A. (1998). Evaluation of immunotherapy in house dust mite asthma, ph.D Thesis, Cairo university , Cairo

[26]. Prasad R, Kumar R, Verma SK, Pandey US. A study of skin sensitivity to various allergens by intradermal test in patients of bronchial asthma. Indian J Allergy Asthma Immunol. 2001;15:17-21.

[27]. Saied, Z.M. (1990). Preliminary pilot survey in house dust mite in Sharqiya Governorate and their relation to allergic bronchial asthma, master's thesis, Zagazig university, Zagazig, 31

[28]. Sattar, H.A., Mobayed, H., Al-Mohammed, A.A., Ibrahim, A.S., Jufairi, A.A., Balamurugan, P., Mary, V.P. and Bener, A. (2003) The pattern of indoor and outdoor respiratory allergens in asthmatic adult patients in a humid and desert newly developed country, Allerg Immunol., 35(8):300-305.

[29]. Schei, M.A. Hessen, J.O. and Lund, E. (2002) House-dust mites and Mattresses, Allergy, 57(6): 538 - 542

[30]. Simons, F.E. (1994). Allergic Rhinobronchitis: The asthma-allergic rhinitis link. J Allergy Clin Immunol.; 104:534-40.

[31]. Siracusa, A., Marabini, A., Sensi, L., Bacoccoli, R., Ripandelli, A., Anulli, R. and Pettinari, L. (1997). Prevalence of asthma and rhinitis in Perugia, Italy, Monaldi Arch Chest Dis. 52(5):434-439.

[32]. Soares, FA., Segundo, GR., Alves, R., Ynoue, LH., Resende, RO., Sopelete, MC., Silva, DA., Sung, SS. and Taketomi, EA (2007). Indoor allergen sensitization profile in allergic patients of the allergy clinic in the University Hospital in Uberlândia, Brazil, Rev Assoc Med Bras. 53(1):25-28.

[33]. Uzel, A., Capan, N., Canbakan, S., Yurdakul, AS. and Dursun, B. (2005). Evaluation of the relationship between cockroach sensitivity and house-dust-mite sensitivity in Turkish asthmatic patients. Respir Med. 99(8):1032-1037.

[34]. Yuen, AP. Cheung, S. Tang, KC. Ho, WK. Wong, BY. Cheung, AC. and Ho, AC (2007) The skin prick test results of 977 patients suffering from chronic rhinitis in Hong Kong, Hong Kong Med J. 13(2):131-136 